\title{
Serotonin receptor gene (HTR2A) T102C polymorphism modulates individuals' perspective taking ability and autistic-like traits
}

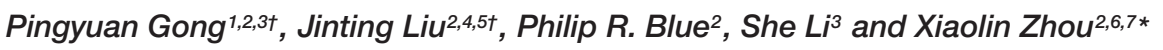 \\ ${ }^{1}$ Key Laboratory of Resource Biology and Biotechnology in Western China, Ministry of Education, Northwest University, \\ Xi'an, China, ${ }^{2}$ Center for Brain and Cognitive Sciences and Department of Psychology, Peking University, Beijing, China, \\ ${ }^{3}$ Laboratory of Medical Molecular Biology, Henan University of Science and Technology, Luoyang, China, ${ }^{4}$ China Center for \\ Special Economic Zone Research, Shenzhen University, Shenzhen, China, ${ }^{5}$ Research Centre for Brain Function and \\ Psychological Science, Shenzhen University, Shenzhen, China, ${ }^{6}$ Key Laboratory of Machine Perception (Ministry of \\ Education), Peking University, Beijing, China, ${ }^{7}$ IDG/McGovern Institute for Brain Research, Peking University, Beijing, China
}

\section{OPEN ACCESS}

Edited by:

Leonhard Schilbach, Max Planck Institute of Psychiatry,

Germany

Reviewed by:

Marcus Ising,

Max Planck Institute for Polymer

Research, Germany

Varun Warrier,

University of Cambridge, UK

*Correspondence:

Xiaolin Zhou

xz104@pku.edu.cn

tThese authors have contributed equally to this work.

Received: 31 July 2015 Accepted: 02 October 2015

Published: 23 October 2015

Citation:

Gong P, Liu J, Blue PR, Li S and Zhou $X$ (2015) Serotonin receptor gene (HTR2A) T102C polymorphism modulates individuals' perspective taking ability and autistic-like traits.

Front. Hum. Neurosci. 9:575. doi: 10.3389/fnhum.2015.00575
Previous studies have indicated that empathic traits, such as perspective taking, are associated with the levels of serotonin in the brain and with autism spectrum conditions. Inspired by the finding that the serotonin receptor 2A gene (HTR2A) modulates the availability of serotonin, this study investigated to what extent HTR2A modulates individuals' perspective taking ability and autistic-like traits. To examine the associations of the functional HTR2A polymorphism T102C (rs6313) with individuals' perspective taking abilities and autistic-like traits, we differentiated individuals according to this polymorphism and measured empathic and autistic-like traits with Interpersonal Reactivity Index (IRI) and Autism-Spectrum Quotient (AQ) scale in 523 Chinese people. The results indicated that this polymorphism was significantly associated with the scores on Perspective Taking and Personal Distress subscales of $\mid \mathrm{RI}$, and Communication subscale of $A Q$. Individuals with a greater number of the $C$ alleles were less likely to spontaneously adopt the point of view of others, more likely to be anxious when observing the pain endured by others, and more likely to have communication problems. Moreover, the genotype effect on communication problems was mediated by individuals' perspective taking ability. These findings provide evidence that the HTR2A T102C polymorphism is a predictor of individual differences in empathic and autistic-like traits and highlight the role of the gene in the connection between perspective taking and autistic-like traits.

\section{Keywords: empathy, perspective taking, autistic-like traits, serotonin, HTR2A}

\section{INTRODUCTION}

Empathy, in the broadest sense, is the lens through which we understand, experience, and respond to the internal states of others (Davis, 1983). It is composed of a variety of skills or components, such as perspective taking (the understanding of another person's beliefs and thoughts, also termed "theory of mind") and empathic response (the emotional response to others' affective states) (Baron-Cohen and Wheelwright, 2004; Batson, 2009; Shamay-Tsoory, 2009). These skills allow 
us to understand and predict others' motives, intentions, thoughts, and emotions, so as to foster and maintain social relationships (Davis and Oathout, 1987). Deficit in empathic ability is a central feature of social behavioral abnormalities. For example, individuals with autism, which is a developmental disorder characterized by restricted interests, stereotyped and repetitive behaviors, as well as deficits in social interaction and communication (Gmitrowicz and Kucharska, 1994), show severe impairment in perspective taking (Baron-Cohen et al., 1985).

Empathic traits are strikingly variable among individuals. Twin studies showed that empathic traits are highly heritable, with a heritability of up to $67 \%$ for perspective taking and $34-47 \%$ for empathic response (Hughes and Cutting, 1999; Knafo et al., 2008), implying that individual differences in empathic components are strongly influenced by individuals' genetic expression. Although previous studies have demonstrated the contribution of genes such as the oxytocin receptor gene and the dopamine beta-hydroxylase gene to individual differences in empathy (Rodrigues et al., 2009; Wu et al., 2012; Gong et al., 2014), most of the genes involved in empathic traits are still under-investigated. In this study, we aimed to examine to what extent the polymorphism of serotonin receptor $2 \mathrm{~A}$ gene (HTR2A) modulates empathic traits, particularly perspective taking ability.

HTR2A is one of the most abundantly expressed serotonin receptors in the brain, with high levels in the cerebral cortical areas, hippocampus, nucleus accumbens, and caudate nucleus (Barnes and Sharp, 1999). This receptor belongs to the G proteincoupled receptor family and is the primary excitatory receptor of serotonin, mainly acting at post-synaptic neurons. In humans, HTR2A is located at 13q14.2. The expression of HTR2A is regulated by several functional polymorphisms (Polesskaya and Sokolov, 2002; Myers et al., 2007), among which T102C (rs6313) is the most studied single nucleotide polymorphism in the gene. Compared with the $\mathrm{T}$ allele, the $\mathrm{C}$ allele leads to lower receptor expressions (Polesskaya and Sokolov, 2002) and lower receptor binding potentials (Turecki et al., 1999), and therefore reduces excitation at post-synaptic neurons (Aghajanian and Marek, 1997).

Although presently there is no study directly investigating the association between HTR2A T102C polymorphism and individual differences in empathic traits, a previous study did show that the serotonin neurotransmission, which could be regulated by this polymorphism, plays a role in empathic traits (Nantel-Vivier et al., 2011). This study, focusing on neurotransmitters involved in social interaction and social inference, has indicated that serotonin is crucial for perspective taking, with enhanced serotonin levels relating to better inference of others' thoughts and feelings in males with a history of aggression. Thus, given the link between HTR2A T102C polymorphism and the serotonin levels in the brain and the link between the serotonin levels and perspective taking, it is possible that the HTR2A polymorphism modulates an individual's perspective taking ability. Moreover, previous studies have indicated that the $\mathrm{C}$ allele of $\mathrm{T} 102 \mathrm{C}$ is associated with poor social functioning in general (Unschuld et al., 2007; Chen et al., 2009; Fraley et al., 2013). The C allele is associated with higher attachment-related anxiety (Fraley et al., 2013), decreased prosocial and affiliative orientations (Unschuld et al., 2007), and less effective aripiprazole treatment on negative symptoms of schizophrenia, including social withdrawal, poor rapport, lack of spontaneity and decreased flow of conversation (Chen et al., 2009). We therefore predict that compared with the $\mathrm{T}$ allele, the $\mathrm{C}$ allele of $\mathrm{T} 102 \mathrm{C}$ is associated with a worse perspective taking ability.

The $\mathrm{C}$ allele could also be a risk allele for autism (Smith et al., 2014). A previous family-based study demonstrated that, compared with healthy siblings, autistic individuals have higher incidences of the $\mathrm{G}$ allele of A-1438G (i.e., rs6311) in HTR2A (Smith et al., 2014). The G allele of A-1438G has an almost complete linkage disequilibrium with the C allele of T102C (Spurlock et al., 1998), with $r^{2}$ of 0.98 in Caucasian populations (Unschuld et al., 2007) and 1.00 in Asian populations (Chen et al., 2009). We thus predict that individuals with the $\mathrm{C}$ allele of T102C are more likely to evidence autistic-like traits. Moreover, the severity of autistic symptoms can be alleviated by perspective taking training (Feng et al., 2008) and impairments in theory of mind/perspective taking ability are underlying causes of social interaction deficits in individuals with autism (Baron-Cohen et al., 1985). Therefore, it is possible that the association between the $\mathrm{C}$ allele and autistic-like traits is mediated by one's ability to take the perspective of others.

\section{MATERIALS AND METHODS}

\section{Participants}

Five hundred and twenty-three unselected students (388 females, mean age $=24.3 \pm 1.4$ years) were recruited from Henan University of Science and Technology, China. They were ethnic Han Chinese without any known ancestors of other ethnic origin. All of them were in the normal range of anxiety symptoms (i.e., scores < 50) as assessed by the Zung Self-Rating Anxiety Scale (Zung, 1971; Wang et al., 1999) and of depressive symptoms as assessed by the Zung Self-Rating Depression Scale (Zung, 1965; Wang et al., 1999), except for four participants who had higher scores $(51,51,57$, and 62 , respectively) beyond the normal range of depressive symptoms. Given that excluding the four participants did not change the pattern of results, we included them in the following reported data analysis. Written informed consents were obtained from each participant. The study was approved by the Ethics Committee of the Department of Psychology, Peking University and performed in accordance with the Declaration of Helsinki.

\section{Genotyping}

We collected 3-5 hairs with hair follicle cells from each participant and extracted genomic DNA from hair follicle cells by Chelex-100 method (De Lamballerie et al., 1994). This way of DNA sampling is more likely to obtain the consent from the human participants as compared to blood sampling, and less likely to be contaminated as compared to saliva sampling. A 242 bp DNA fragment containing T102C (rs6313) in HTR2A gene was produced by polymerase chain reaction $(\mathrm{PCR})$ with the upstream primer, 5'-AACTACGAACTCCCTAA- $3^{\prime}$, and the 
downstream primer, 5'-GTATGTTTCCAGCAAT-3'. The PCR reaction was performed with an initial $5 \mathrm{~min}$ denaturation at $94^{\circ} \mathrm{C}$, followed by 35 cycles of $94^{\circ} \mathrm{C}$ for $30 \mathrm{~s}, 60^{\circ} \mathrm{C}$ for $30 \mathrm{~s}$, $72^{\circ} \mathrm{C}$ for $1 \mathrm{~min}$, and a final extension period at $72^{\circ} \mathrm{C}$ for $5 \mathrm{~min}$. The PCR product was incubated with the restriction enzyme MspI (Fermentas) at $37^{\circ} \mathrm{C}$ overnight in a $5 \mu \mathrm{L}$ digestion system, containing $1.0 \mu \mathrm{L}$ PCR products, $0.40 \mu \mathrm{L}(10 \mathrm{U} / \mu \mathrm{L}) \mathrm{MspI}$, $0.40 \mu \mathrm{L}$ Tango buffer and $3.2 \mu \mathrm{L} \mathrm{H}_{2} \mathrm{O}$. The incubated mixture was analyzed by using $8 \%$ polyacrylamide gel electrophoresis in $220 \mathrm{~V}$ for $2.5 \mathrm{~h}$. The gels were stained with $1.0 \%$ silver nitrate solution, and the genotypes bands in gels were identified by the Bio-imaging Systems software. In the current sample of 523 individuals, the distribution of genotypes ( $\mathrm{CC}=105, \mathrm{CT}=271$, $\mathrm{TT}=147)$ did not deviate from Hardy-Weinberg Equilibrium $\left(\chi^{2}=0.970, p=0.325\right)$. The genotype frequencies were similar to those found in other Chinese Han samples (Zhang et al., 2008; Chen et al., 2009).

\section{Interpersonal Reactivity Index (IRI)}

Empathic traits were measured with the Chinese version (Rong et al., 2010) of the 28-item IRI (Davis, 1983), which is the most commonly used self-report instrument assessing empathy and which is based on a multidimensional approach. The scale consists of four 7-item subscales including Perspective Taking, Fantasy, Empathic Concern, and Personal Distress. Perspective Taking subscale evaluates an individual' s cognitive propensity to spontaneously adopt the point of view of others; Fantasy subscale assesses the extent to which people immerse themselves into the feelings and actions of characters in fictional situations; Empathic Concern subscale measures the feeling of warmth, compassion, and concern in response to the misfortune of others; Personal Distress subscale taps "self-oriented" feelings of personal anxiety and discomfort when observing the pain endured by others. For each item, the respondent selected on a 5-point Likert scale the degree to which the description applied to him/herself, with 0 indicating "does not describe me well" and 4 indicating "describes me very well." The internal consistencies for Perspective Taking, Fantasy, Empathic Concern, and Personal Distress were 0.601, $0.605,0.642$, and 0.684 , respectively. They were comparable to what were reported in a previous study $(0.59 \leq \alpha \leq 0.78)$ (Rong et al., 2010). The total score of each subscale was calculated according to the scoring procedure suggested by Davis (1983). Of note, 178 participants (out of 523) completed the IRI in a previous study (Gong et al., 2014) and they completed the IRI again for this study.

\section{Autism-Spectrum Quotient (AQ)}

Autistic-like traits were measured with the Chinese version (Liu, 2008) of the 50-item AQ (Baron-Cohen et al., 2001), a selfadministered questionnaire for adults of normal intelligence that identifies to what extent the respondent might have features of the core autistic phenotypes. It consists of five 10-item subscales: Social Skill, Attention Switching, Attention to Detail, Communication, and Imagination. Social Skill subscale measures the unwillingness and inability to develop social relationships; Attention Switching subscale assesses the preference to focus on and the inability to shift attention away from stereotyped, repetitive patterns of activities; Attention to Detail subscale evaluates the willingness and ability to notice or remember detail, such as dates and numbers; Communication subscale assesses the unwillingness and inability to initiate or sustain a conversation with others; Imagination subscale measures the unwillingness and inability to engage in symbolic, imaginative activities, including reading fiction, watching dramas, and playing games involving pretending. For each item, the respondent answered 'definitely agree,' 'slightly agree,' 'slightly disagree,' or 'definitely disagree' according to the extent to which the description applied to him/herself. Each item scores one point if the respondent agreed with the description of autistic-like behavior, i.e., poor social skill, poor communication, poor imagination, exceptional attention to detail, poor attention switching/strong focus of attention. The internal consistency for the Chinese version of AQ was 0.578 in the present sample, which is slightly lower than the score $(0.670)$ in a previous study with a large healthy sample (Hurst et al., 2007). The total score of each subscale was calculated according to the scoring procedure suggested by Baron-Cohen et al. (2001). For the total score on AQ, eight participants scored from 32 to 34, at or above the cutoff for distinguishing autistic populations versus non-autistic populations (Baron-Cohen et al., 2001). This is to be expected, as autistic traits are reported to a greater extent in the general populations of Eastern cultures than Western cultures (Liu, 2008; Freeth et al., 2013), which strongly suggests that these individuals would not be diagnosed with autism. In addition, the percentage of autistic-like individuals in the current study was consistent with what has been reported in a previous study (Liu, 2008), so we decided to include these participants in the data analysis.

\section{Statistical Analysis}

To test the effects of the HTR2A T102C polymorphism on empathic and autistic-like traits, we conducted univariate linear regression analyses with the genotypes $(0=\mathrm{CC}, 1=\mathrm{CT}, 2=\mathrm{TT})$ as a single predictor (for the outcome variables, see Table 1). Because of multiple testing ( $n$ tests $=10$ ), to control for the rate of false-positive findings by chance, we adjusted $p$ values using Bonferroni correction. To estimate the probability of correctly rejecting the null hypothesis when it is false $(1-\beta)$, post hoc power analyses were carried out using the program $G^{*}$ power 3.0 (Faul et al., 2007) with the two-tailed alpha level set at 0.05 (uncorrected) or 0.005 (Bonferroni corrected). The power analysis was also used to calculate the minimal detectable effect. Results indicated that the minimum regression coefficient of 0.122 (i.e., the coefficient of determination $R^{2}>1.48 \%$ ) was required for a sample of 523 (two-tailed $\alpha=0.05,1-\beta=0.8$ ).

To test the robustness of the results in the regression analyses, we randomly selected a subsample with a given size (e.g., $N=400$ ) from the total sample 20,000 times and estimated the regression coefficient in each simulated subsample. Then we calculated the probability of the estimated regression coefficients reaching significance in the 20,000 subsamples. The size of the subsample was set at 200,300, 400, or 500 (Table 1).

To test for the mediating role of perspective taking in the association between the HTR $2 A$ T102C polymorphism and communication problems, we bootstrapped the indirect effect 
of the polymorphism on Communication through Perspective Taking 20,000 times using the SPSS version of INDIRECT macro (http://www.afhayes.com/; Preacher and Hayes, 2008) and obtained the bias-corrected $95 \%$ confidence interval of the indirect effect. The indirect effect is considered statistically significant at $p<0.05$ when the $95 \%$ confidence interval does not include zero.

In our previous study, we found an association between a variant $(-1021 \mathrm{C} / \mathrm{T})$ in the $\mathrm{DBH}$ gene and empathic traits, with the CC carriers showing higher scores on the Empathic Concern subscale than the CT/TT carriers (Gong et al., 2014). To examine whether the effects of the T102C polymorphism on empathic and autistic-like traits continued to hold after controlling for the scores on Empathic Concern subscale and/or the $-1021 \mathrm{C} / \mathrm{T}$ polymorphism in the $D B H$ gene, we conducted hierarchical regression analysis: step 1, entering control variables; step 2, entering both control variables and the $\mathrm{T} 102 \mathrm{C}$ polymorphism.

\section{Results}

\section{Direct Effect}

As shown in Table 1, regression analyses revealed that the polymorphism was significantly associated with the total scores on the Perspective Taking subscale and Personal Distress subscale of IRI, and the Communication subscale of $\mathrm{AQ}$ both before and after Bonferroni correction. Individuals with a greater number of the $\mathrm{C}$ alleles, which is associated with lower activity of HTR2A, were less likely to spontaneously adopt the point of view of others, were more likely to be anxious when observing the pain endured by others, and were more likely to have communication problems (Figure 1). Additionally, results also showed that the polymorphism seemed to be associated with scores on the Attention to Detail subscale of $\mathrm{AQ}$, with a greater number of the $\mathrm{C}$ alleles significantly associating with a decreased ability to notice or remember details; however, this result did not survive Bonferroni correction (Table 1).

\section{Mediation Analysis}

Considering that previous studies have demonstrated the causal link between individuals' perspective taking ability and communication problems (Saxton et al., 2013; Wardlow et al., 2014), we conducted a mediation analysis to examine whether the genotype effect on communication would be mediated by individuals' perspective taking abilities. Compared with a regression in which genotype was included as the only predictor of Communication (the genotype effect: $\beta=-0.125, t=-2.880$, $p=0.004$ ), when both genotype and Perspective Taking were included as predictors, the effect of genotype on Communication decreased, $\beta=-0.098, t=-2.285, p=0.023$ (Figure 2). The total indirect effect accounted for $21.6 \%(1-0.098 / 0.125)$ of the genotype effect on Communication. Mediation analysis indicated a significant mediating effect of perspective taking ability on the relationship between HTR2A T102C polymorphism and communication problems, indirect effect estimate $=-0.0075$, $S E=0.0031$, bias-corrected $95 \%$ confidence interval is $[-0.0150$, $-0.0026]$.

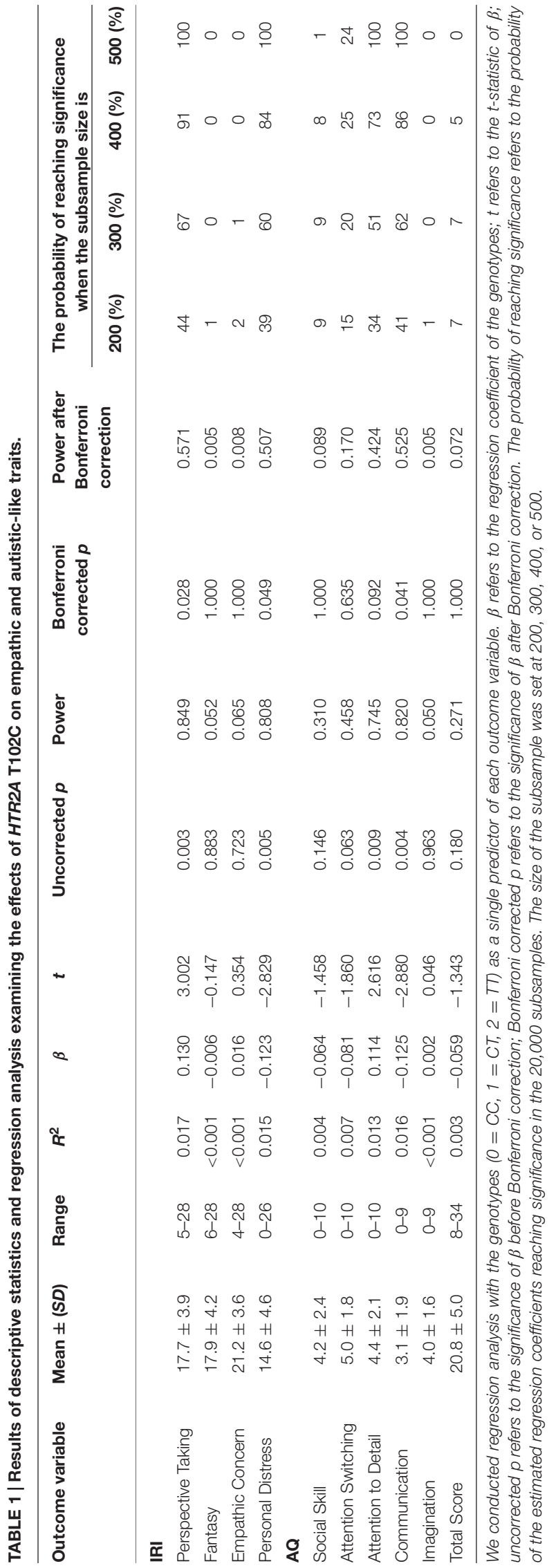


A

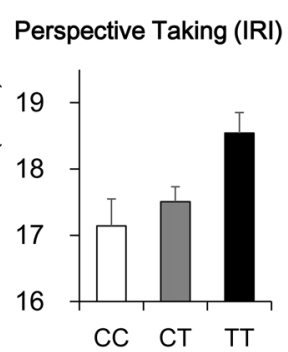

B

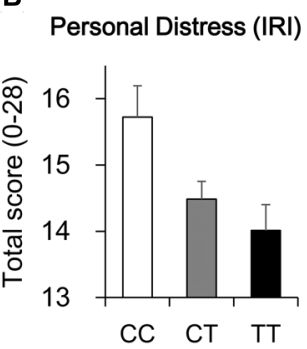

C

Communication (AQ)

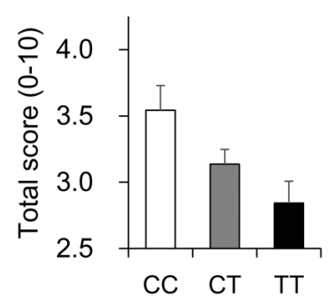

FIGURE 1 | Effects of HTR2A T102C polymorphism on perspective taking and autistic-like traits. (A) Individuals with a greater number of the $\mathrm{C}$ alleles, which is associated with lower activity of HTR2A, were less likely to spontaneously adopt the point of view of others. (B) Individuals with a greater number of the $\mathrm{C}$ alleles were more likely to be anxious when observing the pain endured by others. (C) Individuals with a greater number of the $\mathrm{C}$ alleles were more likely to have communication problems.

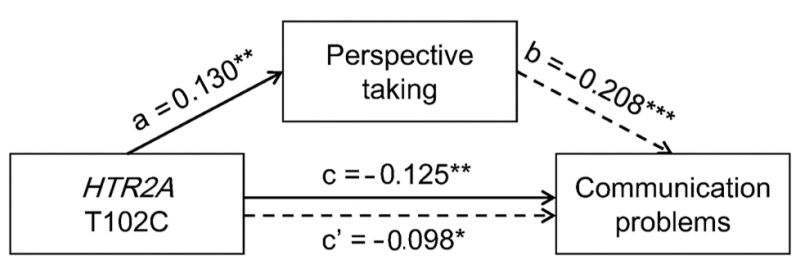

FIGURE 2 | The mediating role of perspective taking ability in the association between HTR2A T102C polymorphism $(0=C C, 1=C T$, $\mathbf{2}=\mathbf{T T}$ ) and communication problems. All estimates are standardized, ${ }^{*} p<0.05,{ }^{* *} p<0.01,{ }^{* * *} p<0.001$.

\section{Supplementary Analysis}

Given the association between a variant $(-1021 \mathrm{C} / \mathrm{T})$ in the $D B H$ gene and empathic traits observed in our previous study (Gong et al., 2014), we included this variant and scores on Empathic Concern in hierarchical regression analysis and found that the effects shown in Figures 1 and $\mathbf{2}$ remained significant after controlling for scores on Empathic Concern and/or the variant in the $D B H$ gene (Tables 2 and $\mathbf{3}$ ).
Of note, 178 out of 523 participants completed the IRI previously in another study (Gong et al., 2014) and they completed the IRI again in the present study. We also examined the effects of the T102C polymorphism on empathic traits after excluding the data of the 178 participants or replacing these data with the scores in their first test. The pattern of the effects on the four subscales of IRI continued to hold (Table 4).

Moreover, results from our simulated subsamples revealed that the effects shown in Figure $\mathbf{1}$ had increased probabilities of reaching significance as the subsample size increased (Table 1); the probability of reaching significance was $84-91 \%$ when the subsample size set at 400 .

\section{DISCUSSION}

The current study investigated to what extent HTR2A T102C polymorphism modulates individuals' empathic and autisticlike traits. As predicted, we found that the individuals with a greater number of the $\mathrm{C}$ alleles, which is associated with lower activity of HTR2A, were less likely to spontaneously

TABLE 2 | Results of hierarchical regression analysis examining the effects of the T102C polymorphism on empathic and autistic-like traits after controlling for the scores on Empathic Concern subscale and/or the $-1021 \mathrm{C} / \mathrm{T}$ polymorphism $(0=\mathrm{CT} / \mathrm{TT}, 1=\mathrm{CC})$ in the $D B H \mathrm{gene}$.

\begin{tabular}{|c|c|c|c|c|c|}
\hline Outcome variable & Control variable(s) & $R^{2}$ change & $F$ change & $\beta$ & Uncorrected $p$ \\
\hline \multirow[t]{3}{*}{ IRI Perspective Taking } & IRI Empathic Concern & 0.016 & 8.992 & 0.127 & 0.003 \\
\hline & $-1021 \mathrm{C} / \mathrm{T}$ polymorphism & 0.020 & 10.368 & 0.142 & 0.001 \\
\hline & $\begin{array}{l}\text { IRI Empathic Concern and the } \\
-1021 \mathrm{C} / \mathrm{T} \text { polymorphism }\end{array}$ & 0.018 & 9.999 & 0.136 & 0.002 \\
\hline \multirow[t]{3}{*}{ IRI Personal Distress } & IRI Empathic Concern & 0.016 & 8.618 & -0.126 & 0.003 \\
\hline & -1021C/T polymorphism & 0.016 & 8.149 & -0.126 & 0.004 \\
\hline & $\begin{array}{l}\text { IRI Empathic Concern and the } \\
-1021 \mathrm{C} / \mathrm{T} \text { polymorphism }\end{array}$ & 0.017 & 9.025 & -0.130 & 0.003 \\
\hline \multirow[t]{3}{*}{ AQ Communication } & IRI Empathic Concern & 0.015 & 8.175 & -0.124 & 0.004 \\
\hline & -1021C/T polymorphism & 0.016 & 8.375 & -0.127 & 0.004 \\
\hline & $\begin{array}{l}\text { IRI Empathic Concern and the } \\
-1021 \mathrm{C} / \mathrm{T} \text { polymorphism }\end{array}$ & 0.016 & 8.145 & -0.125 & 0.004 \\
\hline
\end{tabular}

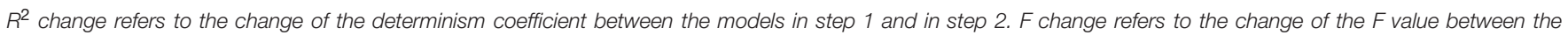
models in step 1 and in step 2. $\beta$ refers to the regression coefficient of the T102C polymorphism; uncorrected $p$ refers to the significance of $\beta$ without correction. 
TABLE 3 | Results of mediation analysis after controlling for the scores on Empathic Concern subscale and/or the $-1021 \mathrm{C} / \mathrm{T}$ polymorphism in the $D B H$ gene.

\begin{tabular}{lccc}
\hline Control variable(s) & $\begin{array}{c}\text { Indirect effect } \\
\text { estimate }\end{array}$ & SE & $\begin{array}{c}\text { Bias-corrected 95\% } \\
\text { confidence interval }\end{array}$ \\
\hline IRI Empathic Concern & -0.0071 & 0.0030 & {$[-0.0145,-0.0024]$} \\
$-1021 \mathrm{C} / \mathrm{T}$ & -0.0083 & 0.0032 & {$[-0.0161,-0.0032]$} \\
$\begin{array}{l}\text { polymorphism } \\
\text { IRI Empathic Concern }\end{array}$ & -0.0077 & 0.0031 & {$[-0.0154,-0.0029]$} \\
$\begin{array}{l}\text { and the }-1021 \mathrm{C} / \mathrm{T} \\
\text { polymorphism }\end{array}$ & & & \\
\hline
\end{tabular}

adopt the point of view of others and more likely to be anxious when observing the pain endured by others. We also found that individuals with a greater number of the $\mathrm{C}$ alleles were more likely to have communication problems, an autisticlike trait. Further analysis showed that the genotype effect on communication is mediated by individuals' perspective taking abilities.

Previous studies have demonstrated that the reduced availability of HTR2A impairs empathy-related behaviors, such as social communication (Murphy et al., 2006) and prosocial and affiliated orientations (Gerretsen et al., 2010). The present study extended these findings by suggesting that the serotonin receptor gene, HTR2A, which regulates the serotonin levels in the brain, to a certain extent, is associated with individual differences in empathic traits. Individuals with a greater number of the $\mathrm{C}$ alleles of HTR2A T102C polymorphism, which is related to reduced excitation at post-synaptic neurons (Aghajanian and Marek, 1997), showed decreased perspective taking ability and increased personal distress. On the surface, these findings are similar to those reported in two recent studies showing the genotype effects of the promoter region (5-HTTLPR) of the serotonin transporter gene (5-HTT) on self-reported empathic traits (Pełka-Wysiecka et al., 2012) and on physiological responses when observing others in distress (Gyurak et al., 2012). However, HTR2A and 5-HTT may have different mechanisms of regulating the serotonin availability, considering their differential distributions in pre- and post-synaptic membranes.
HTR2A receptors are mainly distributed at post-synaptic membranes, whereas 5-HTT proteins are mainly distributed at pre-synaptic membranes (Zhou et al., 1998). The effect of HTR2A gene on empathy may result from the role of T102C in spontaneous excitatory postsynaptic potentials while the effect of 5-HTT gene on empathy may be attributed to the impact of 5-HTTLPR on the reuptake of serotonin into pre-synaptic membranes.

Consistent with the previous study suggesting the role of HTR2A T102C polymorphism in the devolvement of autistic symptoms (Smith et al., 2014), we found that the polymorphism underlies individual differences in autistic-like traits in normal adults. This finding extends our knowledge about the impact of this polymorphism on autistic symptoms, particularly communication problems, both in individuals diagnosed with autism to individuals who do not meet the criteria for autism/healthy populations. A previous study indicated that among the subscales of $\mathrm{AQ}$, communication problems and social skills in autistic-like traits differentiated the parents with autistic children from those without autistic children (Bishop et al., 2004). It is possible that the association between the $\mathrm{C}$ allele and communication problems is one of the causes underlying the increased incidences of the $\mathrm{C}$ allele in autistic children.

In line with the previous studies showing the association between the $\mathrm{C}$ allele and poor social functioning (Unschuld et al., 2007; Fraley et al., 2013), this study found that the $\mathrm{C}$ allele was associated with autistic-like traits and impaired perspective taking ability. Our findings implicate the overlapping genetic basis underlying the individual differences in empathic traits and autistic symptoms. Moreover, our mediation analysis showed that perspective taking mediated the association between HTR2A T102C polymorphism and communication problems. Perspective taking ability may not only promote communication skills through facilitating the accuracy of predicting others' behaviors and reactions (Tanida and Yamagishi, 2004; Galinsky et al., 2008) but may also increase the willingness to communicate with others by reducing the stereotype and prejudice against others (Galinsky et al., 2008; Wang et al., 2012). It is thus possible that individuals with a greater number of the $\mathrm{C}$ allele are more likely

TABLE 4 | Results of regression analysis examining the effects of HTR2A T102C on empathic traits after excluding the 178 participants who participated Gong et al. (2014) or replacing these data with the scores in their first test.

\begin{tabular}{|c|c|c|c|c|c|c|}
\hline Outcome variable & Mean $\pm(S D)$ & Range & $R^{2}$ & $\beta$ & $t$ & Uncorrected $p$ \\
\hline \multicolumn{7}{|c|}{ Excluding the 178 participants } \\
\hline Perspective taking & $17.8 \pm 3.9$ & $5-28$ & 0.027 & 0.164 & 3.072 & 0.002 \\
\hline Fantasy & $17.8 \pm 4.4$ & $7-28$ & $<0.001$ & -0.003 & -0.061 & 0.951 \\
\hline Empathic concern & $21.0 \pm 3.7$ & $4-28$ & 0.001 & 0.031 & 0.568 & 0.571 \\
\hline Personal distress & $14.7 \pm 4.6$ & $4-26$ & 0.019 & -0.138 & -2.572 & 0.011 \\
\hline \multicolumn{7}{|c|}{ Replacing the data with the scores in their first test } \\
\hline Perspective taking & $17.7 \pm 3.9$ & $5-28$ & 0.016 & 0.127 & 2.926 & 0.004 \\
\hline Fantasy & $17.8 \pm 4.3$ & $6-28$ & $<0.001$ & -0.022 & -0.509 & 0.611 \\
\hline Empathic concern & $21.0 \pm 3.6$ & $4-28$ & 0.003 & 0.054 & 1.226 & 0.221 \\
\hline Personal distress & $14.8 \pm 4.6$ & $3-26$ & 0.015 & -0.123 & -2.839 & 0.005 \\
\hline
\end{tabular}


to misunderstand the intentions and behaviors of others and more likely to have difficulties in communicating with others. Our findings suggest a possible psychobiological mechanism underlying the genotype effect on deficits in social interactions.

Several limitations of this study should be noted. First, we demonstrated small effects of a single polymorphism on empathic and autistic traits while these traits are likely to be influenced by multiple polymorphisms (Rodrigues et al., 2009; Wu et al., 2012; Gong et al., 2014) and by a variety of non-genetic factors (O'Reilly and Peterson, 2014). More systematic studies are needed to simultaneously take into consideration genetic and environmental factors underscoring individual differences in empathic and autistic traits. Second, the present study relied on self-report questionnaires which require the participants to be introspective to provide accurate response to the items. The lack of introspective ability and the influence of social desirability may add noises to the measurement, thereby leading to over- or under-estimation of the contribution of the HTR $2 A$ T102C polymorphism to individuals' empathic and autistic traits. Third, our power analyses suggested that a genotype effect accounting for less than $1.48 \%$ of the phenotypic variance would not be detected because of the medium sample size $(N=523)$ in the present study. As the effect size of a single polymorphism for a complex trait is relatively small (Lander, 2011; Hewitt, 2012), this study might suffer from the low statistical power to distinguish some small but true effects from random chance. Finally, the findings do not have a direct replication in a second sample, a recommended procedure for screening false findings in candidate gene association studies (Hewitt, 2012). To substantiate our claims, we randomly selected subsamples from the total sample and calculated the probability of obtaining significant effects in these samples. We found that our findings have a high probability to be replicated in subsamples of enough size. We have also applied

\section{REFERENCES}

Aghajanian, G. K., and Marek, G. J. (1997). Serotonin induces excitatory postsynaptic potentials in apical dendrites of neocortical pyramidal cells. Neuropharmacology 36, 589-599. doi: 10.1016/S0028-3908(97)00051-8

Barnes, N. M., and Sharp, T. (1999). A review of central 5-HT receptors and their function. Neuropharmacology 38, 1083-1152. doi: 10.1016/S00283908(99)00010-6

Baron-Cohen, S., Leslie, A. M., and Frith, U. (1985). Does the autistic child have a "theory of mind"? Cognition 21, 37-46. doi: 10.1016/0010-0277(85)90022-8

Baron-Cohen, S., and Wheelwright, S. (2004). The empathy quotient: an investigation of adults with asperger syndrome or high functioning autism, and normal sex differences. J. Autism Dev. Disord. 34, 163-175. doi: 10.1023/B:JADD.0000022607.19833.00

Baron-Cohen, S., Wheelwright, S., Skinner, R., Martin, J., and Clubley, E. (2001). The Autism-Spectrum Quotient (AQ): evidence from asperger syndrome/highfunctioning autism, males and females, scientists and mathematicians. J. Autism Dev. Disord. 31, 5-17. doi: 10.1023/A:1005653411471

Batson, C. D. (2009). "These things called empathy: eight related but distinct phenomena," in The Social Neuroscience of Empathy, eds J. Decety and W. Ickes (Cambridge, MA: The MIT Press), 3-16.

Bishop, D. V. M., Maybery, M., Maley, A., Wong, D., Hill, W., and Hallmayer, J. (2004). Using self-report to identify the broad phenotype in parents of children with autistic spectrum disorders: a study using the Autism-Spectrum
Bonferroni correction to control for false positives in multiple testing.

\section{CONCLUSION}

By differentiating individuals according to the polymorphism of HTR2A T102C and by measuring empathic and autistic-like traits with IRI and AQ scale, we demonstrated the impact of HTR2A gene on individuals' empathic traits and social communication in a general population. Our findings highlight the role of the HTR2A gene in social functioning and the connection between perspective taking and autistic-like traits.

\section{AUTHOR CONTRIBUTIONS}

PG and JL contributed equally to this work. PG, JL, and XZ designed the study. PG, JL, PB, and XZ wrote the manuscript. PG, JL, and SL performed the experiment and analyzed the data.

\section{FUNDING}

This study was supported by grants from National Basic Research Program of China (973 Program: 2015CB856400) and National Natural Science Foundation of China $(30970889,30110972)$ to $\mathrm{XZ}$ and from Western Resource Biology and Modern Biological Technological Lab Open Foundation of Northwest University (K00114 and JS11004) to PG.

\section{ACKNOWLEDGMENT}

We thank Mr. Peizhe Zhang, Miss Yunxia He, and Miss Lin Lei for their assistance in data collection.

Quotient. J. Child Psychol. Psychiatry 45, 1431-1436. doi: 10.1111/j.14697610.2004.00325.x

Chen, S. F., Shen, Y. C., and Chen, C. H. (2009). HTR2A A-1438G/T102C polymorphisms predict negative symptoms performance upon aripiprazole treatment in schizophrenic patients. Psychopharmacology (Berl.) 205, 285-292. doi: 10.1007/s00213-009-1538-z

Davis, M. H. (1983). Measuring individual differences in empathy: evidence for a multidimensional approach. J. Pers. Soc. Psychol. 44, 113-126. doi: 10.1037//0022-3514.44.1.113

Davis, M. H., and Oathout, H. A. (1987). Maintenance of satisfaction in romantic relationships: empathy and relational competence. J. Pers. Soc. Psychol. 53, 397-410. doi: 10.1037/0022-3514.53.2.397

De Lamballerie, X., Chapel, F., Vignoli, C., and Zandotti, C. (1994). Improved current methods for amplification of DNA from routinely processed liver tissue by PCR. J. Clin. Pathol. 47, 466-467. doi: 10.1136/jcp.47.5.466

Faul, F., Erdfelder, E., Lang, A.-G., and Buchner, A. (2007). G* Power 3: a flexible statistical power analysis program for the social, behavioral, and biomedical sciences. Behav. Res. Methods 39, 175-191. doi: 10.3758/BF03193146

Feng, H., Lo, Y. Y., Tsai, S. L., and Cartledge, G. (2008). The effects of theory-of-mind and social skill training on the social competence of a sixth-grade student with autism. J. Posit. Behav. Interv. 10, 228-242. doi: 10.1177/1098300708319906

Fraley, R. C., Roisman, G. I., Booth-LaForce, C., Owen, M. T., and Holland, A. S. (2013). Interpersonal and genetic origins of adult attachment styles: a 
longitudinal study from infancy to early adulthood. J. Pers. Soc. Psychol. 104, 817-838. doi: 10.1037/a0031435

Freeth, M., Sheppard, E., Ramachandran, R., and Milne, E. (2013). A cross-cultural comparison of autistic traits in the UK, India and Malaysia. J. Autism Dev. Disord. 43, 2569-2583. doi: 10.1007/s10803-013-1808-9

Galinsky, A. D., Maddux, W. W., Gilin, D., and White, J. B. (2008). Why it pays to get inside the head of your opponent: the differential effects of perspective taking and empathy in negotiations: research article. Psychol. Sci. 19, 378-384. doi: 10.1111/j.1467-9280.2008.02096.x

Gerretsen, P., Graff-Guerrero, A., Menon, M., Pollock, B. G., Kapur, S., Vasdev, N., et al. (2010). Is desire for social relationships mediated by the serotonergic system in the prefrontal cortex? An [18F] setoperone PET study. Soc. Neurosci. 5, 375-383. doi: 10.1080/17470911003589309

Gmitrowicz, A., and Kucharska, A. (1994). Developmental disorders in the fourth edition of the American classification: diagnostic and statistical manual of mental disorders (DSM IV - optional book). Psychiatr. Pol. 28, 509-521.

Gong, P., Liu, J., Li, S., and Zhou, X. (2014). Dopamine beta-hydroxylase gene modulates individuals' empathic ability. Soc. Cogn. Affect. Neurosci. 9, 13411345. doi: $10.1093 /$ scan/nst122

Gyurak, A., Haase, C. M., Sze, J., Goodkind, M. S., Coppola, G., Lane, J., et al. (2012). The effect of the serotonin transporter polymorphism (5-HTTLPR) on empathic and self-conscious emotional reactivity. Emotion 13, 25-35. doi: $10.1037 / \mathrm{a} 0029616$

Hewitt, J. K. (2012). Editorial policy on candidate gene association and candidate gene-by-environment interaction studies of complex traits. Behav. Genet. 42, 1-2. doi: 10.1007/s10519-011-9504-Z

Hughes, C., and Cutting, A. L. (1999). Nature, nurture, and individual differences in early understanding of mind. Psychol. Sci. 10, 429-432. doi: 10.1111/14679280.00181

Hurst, R. M., Mitchell, J. T., Kimbrel, N. A., Kwapil, T. K., and Nelson-Gray, R. O. (2007). Examination of the reliability and factor structure of the Autism Spectrum Quotient (AQ) in a non-clinical sample. Pers. Individ. Dif. 43, 1938-1949. doi: 10.1016/j.paid.2007.06.012

Knafo, A., Zahn-Waxler, C., Van Hulle, C., Robinson, J. L., and Rhee, S. H. (2008). The developmental origins of a disposition toward empathy: genetic and environmental contributions. Emotion 8, 737-752. doi: 10.1037/a0014179

Lander, E. S. (2011). Initial impact of the sequencing of the human genome. Nature 470, 187-197. doi: 10.1038/nature09792

Liu, M. (2008). Screening adults for asperger syndrome and high-functioning autism by using the Autism-Spectrum Quotient (AQ) (Mandarin Version) [in Chinese]. Bull. Spec. Educ. 33, 73-92.

Murphy, D. G. M., Daly, E., Schmitz, N., Toal, F., Murphy, K., Curran, S., et al. (2006). Cortical serotonin 5-HT2A receptor binding and social communication in adults with Asperger's syndrome: an in vivo SPECT study. Am. J. Psychiatry 163, 934-936. doi: 10.1176/appi.ajp.163.5.934

Myers, R. L., Airey, D. C., Manier, D. H., Shelton, R. C., and Sanders-Bush, E. (2007). Polymorphisms in the regulatory region of the human serotonin 5HT2A receptor gene (HTR2A) influence gene expression. Biol. Psychiatry 61, 167-173. doi: 10.1016/j.biopsych.2005.12.018

Nantel-Vivier, A., Pihl, R. O., Young, S. N., Parent, S., Bélanger, S. A., Sutton, R., et al. (2011). Serotonergic contribution to boys' behavioral regulation. PLoS ONE 6:e20304. doi: 10.1371/journal.pone.0020304

O'Reilly, J., and Peterson, C. C. (2014). Theory of Mind at home: linking authoritative and authoritarian parenting styles to children's social understanding. Early Child Dev. Care 184, 1-14. doi: 10.1080/03004430.2014.894034

Pełka-Wysiecka, J., Zietek, J., Grzywacz, A., Kucharska-Mazur, J., Bienkowski, P., and Samochowiec, J. (2012). Association of genetic polymorphisms with personality profile in individuals without psychiatric disorders. Prog. Neuropsychopharmacol. Biol. Psychiatry 39, 40-46. doi: 10.1016/j.pnpbp.2012.04.009

Polesskaya, O. O., and Sokolov, B. P. (2002). Differential expression of the " $\mathrm{C}$ " and "T" alleles of the 5-HT2A receptor gene in the temporal cortex of normal individuals and schizophrenics. J. Neurosci. Res. 67, 812-822. doi: 10.1002/jnr.10173

Preacher, K. J., and Hayes, A. F. (2008). Asymptotic and resampling strategies for assessing and comparing indirect effects in multiple mediator models. Behav. Res. Methods 40, 879-891. doi: 10.3758/BRM.40.3.879

Rodrigues, S. M., Saslow, L. R., Garcia, N., John, O. P., and Keltner, D. (2009). Oxytocin receptor genetic variation relates to empathy and stress reactivity in humans. Proc. Natl. Acad. Sci. U.S.A. 106, 21437-21441. doi: 10.1073/pnas.0909579106

Rong, X., Sun, B., Huang, X., Cai, M., and Li, W. (2010). Reliabilities and validities of Chinese version of interpersonal reactivity index [in Chinese]. Chin. J. Clin. Psychol. 18, 158-160. doi: 10.16128/j.cnki.1005-3611.2010. 02.020

Saxton, M. E., Younan, S. S., and Lah, S. (2013). Social behaviour following severe traumatic brain injury: contribution of emotion perception deficits. Neurorehabilitation 33, 263-271. doi: 10.3233/ NRE-130954

Shamay-Tsoory, S. G. (2009). "Empathic processing: its cognitive and affective dimensions and neuroanatomical basis," in The Social Neuroscience of Empathy, eds J. Decety and W. Ickes (Cambridge, MA: The MIT Press), 215-232.

Smith, R. M., Banks, W., Hansen, E., Sadee, W., and Herman, G. E. (2014). Familybased clinical associations and functional characterization of the serotonin $2 \mathrm{~A}$ receptor gene (HTR2A) in autism spectrum disorder. Autism Res. 7, 459 -467. doi: 10.1002/aur.1383

Spurlock, G., Heils, A., Holmans, P., Williams, J., D’Souza, U. M., Cardno, A., et al. (1998). A family based association study of T102C polymorphism in 5HT2A and schizophrenia plus identification of new polymorphisms in the promoter. Mol. Psychiatry 3, 42-49. doi: 10.1038/sj.mp.4000342

Tanida, S., and Yamagishi, T. (2004). The effect of empathy on accuracy of behavior prediction in social exchange situation. Shinrigaku Kenkyu 74, 512-520. doi: 10.4992/jjpsy.74.512

Turecki, G., Brière, R., Dewar, K., Antonetti, T., Lesage, A. D., Séguin, M., et al. (1999). Prediction of level of serotonin 2A receptor binding by serotonin receptor $2 \mathrm{~A}$ genetic variation in postmortem brain samples from subjects who did or did not commit suicide. Am. J. Psychiatry 156, 1456-1458.

Unschuld, P. G., Ising, M., Erhardt, A., Lucae, S., Kloiber, S., Kohli, M., et al. (2007). Polymorphisms in the serotonin receptor gene HTR2A are associated with quantitative traits in panic disorder. Am. J. Med. Genet. B Neuropsychiatr. Genet. 144, 424-429. doi: 10.1002/ajmg.b.30412

Wang, C. S., Ku, G., Tai, K., and Galinsky, A. D. (2012). Stupid doctors and smart construction workers: perspective-taking reduces stereotyping of both negative and positive targets. Soc. Psychol. Personal. Sci. 5, 430-436. doi: $10.1177 / 1948550613504968$

Wang, X., Wang, X., and Ma, H. (1999). Manual of Mental Health Rating Scale. Beijing: Chinese Mental Health Journal Publisher.

Wardlow, L., Ivanova, I., and Gollan, T. H. (2014). The cognitive mechanisms underlying perspective taking between conversational partners: evidence from speakers with Alzheimer[U+05F3]s disease. Neuropsychologia 56, 184-195. doi: 10.1016/j.neuropsychologia.2014.01.013

$\mathrm{Wu}, \mathrm{N} ., \mathrm{Li}, \mathrm{Z}$., and Su, Y. (2012). The association between oxytocin receptor gene polymorphism (OXTR) and trait empathy. J. Affect. Disord. 138, 468-472. doi: 10.1016/j.jad.2012.01.009

Zhang, J., Shen, Y., He, G., Li, X., Meng, J., Guo, S., et al. (2008). Lack of association between three serotonin genes and suicidal behavior in Chinese psychiatric patients. Prog. Neuropsychopharmacol. Biol. Psychiatry 32, 467-471. doi: 10.1016/j.pnpbp.2007.09.019

Zhou, F. C., Tao-Cheng, J. H., Segu, L., Patel, T., and Wang, Y. (1998). Serotonin transporters are located on the axons beyond the synaptic junctions: anatomical and functional evidence. Brain Res. 805, 241-254. doi: 10.1016/S00068993(98)00691-X

Zung, W. W. K. (1965). A self-rating depression scale. Arch. Gen. Psychiatry 12, 63-70. doi: 10.1001/archpsyc.1965.01720310065008

Zung, W. W. K. (1971). A rating instrument for anxiety disorders. Psychosomatics 12, 371-379. doi: 10.1016/S0033-3182(71)71479-0

Conflict of Interest Statement: The authors declare that the research was conducted in the absence of any commercial or financial relationships that could be construed as a potential conflict of interest.

Copyright (c) 2015 Gong, Liu, Blue, Li and Zhou. This is an open-access article distributed under the terms of the Creative Commons Attribution License (CC BY). The use, distribution or reproduction in other forums is permitted, provided the original author(s) or licensor are credited and that the original publication in this journal is cited, in accordance with accepted academic practice. No use, distribution or reproduction is permitted which does not comply with these terms. 